Шиян А. А. Онтологические и методологические принципы феноменологического подхода Эдмунда Гуссерля // Философия. ЖКурнал Высшей школы экономики. - 2017. T. I, № 3. - C. 63-79.

\title{
АннА Шиян*
}

\section{ОНТОЛОГИЧЕСКИЕ И МЕТОАОЛОГИЧЕСКИЕ ПРИНЦИПЫ ФЕНОМЕНОЛОГИЧЕСКОГО ПОАХОАА ЭАМУНАА ГУССЕРАЯ**}

Аннотация: Признавая оправданность множества интерпретаций феноменологии Гуссерля, автор статьи предлагает и обосновывает собственный подход к философии Гуссерля, основанный на работах К. Хельда, В.И. Молчанова и $\Lambda$. Тенгели. С этой целью, прежде всего, формулируются онтологические предпосылки философии Гуссерля, которые определяли его исследования, хотя и не всегда эксплицитно формулировались самим феноменологом. К таким предпосылкам относится, в первую очередь, признание существования мира как совокупности предметов, их свойств и отношений. Далее автор останавливается на принципах и методах феноменологического исследования. При этом принимаются в расчет не только и не столько декларации принципов Гуссерля им самим, но их конкретное применение и осуществление в реальной феноменологической работе. В результате этого формулируются «новые» (не названные самим Гуссерлем) принципы феноменологического подхода и переосмысляются «старые» и хорошо известные. В статье особое внимание уделяется методу эпохе́ и принципу работы в двух установках: естественной и феноменологической. Так, одной из важнейших функций эпохе́ автор считает выявление и фиксацию предпосылок естественной установки, часть из которых переносится в феноменологическую установку. В статье также показывается, как онтологические и методологические предпосылки Гуссерля проявляются в его исследованиях, посвященных конкретным предметным областям - изучению сознания или разрешению проблем теории познания и изучения окружающего мира. В ходе этих рассмотрений автор обозначает моменты, в которых Гуссерль отходит от своих принципов и следует Аругой, конструктивистской стратегии. Речь идет, прежде всего, о понимании интенциональности, понятиях смысла и ноэмы и применении метода редукции. В заключении, оценивая собственную стратегию исследования философии Гуссерля, автор обозначает свой историко-философский подход как презентизм.

Ключевые слова: феноменология, Гуссерль, опыт сознания, редукция, феноменологическая установка.

\section{1. ВВЕДЕНИЕ}

В рамках феноменологического движения нет ни одного принципа, безоговорочно признаваемого всеми феноменологами в качестве основного, который можно было бы рассматривать в качестве некоторой

*Шиян Анна Александровна, к. филос. н., доцент кафедры социальной философии философского факультета РГГУ, annasamoikina@yandex.ru.

** (C) Шиян, А.А.(C) Философия. Журнал Высшей школы экономики. 
«визитной карточки» феноменологии. Об этом говорит известная поговорка: «Феноменологий столько, сколько феноменологов». Но это, конечно, преувеличение. Можно выделить несколько «основных» интерпретаций феноменологии Гуссерля. Я назову две из них. Согласно первой интерпретации, феноменология - это наука о трансцендентально-чистом сознании с центром в «чистом Я». Это сознание является основанием, отправным пунктом для изучения других видов бытия. Такого понимания феноменологии придерживался, например, русский исследователь А.Г. Черняков. Согласно второй интерпретации, сущностный признак феноменологии - это интуитивное схватывание бытия в его сущностных формах. Так думали, например, реалфеноменологи и, отчасти, русский философ Шпет.

Я хотела бы здесь представить третье понимание феноменологии, которое основывается в значительной степени на работах и лекциях Л. Тенгели, В. Молчанова, К. Хельда ${ }^{1}$. Согласно этому пониманию, феноменология представляет собой особый философский подход, требующий для решения некоторой проблемы обращения к тому собственному повседневному опыту, в котором эта проблема встречается, или, другими словами, к тому, как эта проблема дана в опыте «Первого лица». На это обращают внимание Захави и Галлахер в книге «Феноменологический разум» (Gallagher and Zahavi, 2012: 7, 99-100, 190-195), в которой они отличают феноменологический опыт «Первого лица» от опыта «Третьего лица», которым характеризуется научное познание. Это понимание, как, впрочем, и другие толкования, основывается на текстах Гуссерля. «Очевидно, что я, как философски начинающий, ввиду того, что я устремлен к предполагаемой цели подлинной науки, не могу высказывать или полагать значимым ни одного суждения, которое я не почерпнул бы из очевидности, из опыта, в котором соответствующие вещи и положения вещей присутствуют для меня как они сами»,так звучит формулировка «первого методического принципа» в «Картезианских медитациях» (Гуссерль, Молчанов, 2010: 26). То есть доступ к действительности, к тому, что реально существует, мы получаем не благодаря сущностной интуиции (как у реалфеноменологов) и не благодаря логическому понятию (как у Гегеля), а через обыденный опыт, частным случаем которого для Гуссерля выступает опыт сознания.

Учитывая, во-первых, что жизненный мир для Гуссерля-это, прежде всего, мир нашего повседневного опыта, и, во-вторых, что начиная

\footnotetext{
${ }^{1}$ См., например, Молчанов, 2007; Held, 1992; Tengelyi, 2014.
} 
со своих самых ранних текстов и заканчивая поздними рукописями, Гуссерль обращался для решения своих задач к исследованию опыта именно обыденного сознания, следует сделать вывод: никакого «поворота» к жизненному миру в поздние годы у Гуссерля не происходит, просто в 3о-е гг. Гуссерль более четко формулирует то, чем занимался всю жизнь. Соответственно, деление на «раннего» и «позднего» Гуссерля не имеет смысла. Конечно, в разные периоды творчества на первый план в его исследованиях выходят разные идеи, но, я полагаю, нельзя однозначно сказать, что поздний период творчества Гуссерля кардинально отличается от раннего в методологическом плане.

\section{2. ОНТОЛОГИЧЕСКИЕ ПРЕДПОСЫЛКИ ФЕНОМЕНОЛОГИИ ГУССЕРЛЯ}

Мне хотелось бы отметить некоторые онтологические предпосылки философии Гуссерля, важные для развиваемого мной понимания феноменологии. Эти предпосылки в той или иной степени определяли его исследования, хотя многие из них не всегда явно артикулировались, а некоторые не формулировались эксплицитно никогда.

K важнейшим предпосылкам гуссерлевской феноменологии относятся признание существования мира и понимание мира как совокупности вещей, их свойств и отношений. На тезисе о существовании мира я не буду останавливаться подробно ${ }^{2}$, лишь отмечу, что упреки Гуссерля в трансцендентальном идеализме - например, Р. Ингардена, - не учитывают того, что идеализм Гуссерля носит исключительно методологический, или, говоря его словами, познавательный характер. «Очевидно, что в познавательном плане бытие $E g o$ предшествует для меня всякому объективному бытию: в определенном смысле оно есть основа и почва, на которой развертывается весь процесс объективного познания» (Гуссерль, Молчанов, 2010: 42), - пишет Гуссерль в «Картезианских медитациях». Следует заметить, что слово «бытие» Гуссерль здесь использует как метафору. Этот случай отнюдь не является исключением. «Бытие» в качестве метафоры Гуссерль употребляет даже в своей программной работе «Идеи к чистой феноменологии и феноменологической философии. Книга І», где он пишет об абсолютном бытии сознания в отличие от относительного бытия мира (Гуссерль, Михайлов, 2002: 143-152).

Итак, мы застаем мир уже готовым и вполне определенным; сознание со своими трансцендентальными (то есть общими) структурами обеспечивает нам лишь доступ к нему. Однако мир, в котором мы

${ }^{2}$ См. Шиян, 2015: 213-233. 
живем, сформировался именно таким, а не иным, в ходе культурно-исторического развития и является результатом «работы» предшествующих поколений, или, в трактовке Гуссерля, результатом деятельности трансцендентальной субъективности, которая по своей сути является интерсубъективностью. Исторический характер трансцендентальной субъективности особенно ярко подчеркивается Гуссерлем в текстах позднего периода: «Кризис европейских наук и трансцендентальная феноменология» (Гуссерль, Скляднев, 2004), «Начало геометрии» (Гуссерль, Маяцкий, 1996), «Первая философия» (Husserl, 1959) и других. И именно этот исторический характер позволяет утверждать, что реальное существование вещей - для Гуссерля - зависит по своей природе не от человеческой, а от трансцендентальной субъективности ${ }^{3}$ Здесь важно подчеркнуть, что историчность трансцендентальной субъективности не только подразумевает различение индивидуального и коллективного (социально-культурного) аспектов сознания, но и в некотором смысле выводит нас за пределы сознания, поскольку под трансцендентальной субъективностью Гуссерль понимает не только опыт сознания, но и опыт совместной деятельности, коммуникации, совместного проживания.

Что касается второй предпосылки, то, несмотря на присутствие в разные периоды творчества Гуссерля разных пониманий мира, толкование мира как совокупности вещей, их свойств и отношений между ними никогда не исчезало из его поля зрения.

Наиболее важной мне представляется предпосылка, которую Гуссерль сам никогда прямо не фиксировал, но которая следует из его понимания основного свойства сознания - интенциональности. Согласно этому свойству, сознание человека всегда предметно. С этим связано для Гуссерля, на мой взгляд, то, что мир нам дан всегда уже осмысленным, что в обыденной жизни человек воспринимает мир, живет и действует вполне разумно. В феноменологической установке мы можем удостовериться в предметностях естественной- обыденной или научной - установки и различить то, что в естественной установке мы не различали, то есть увидеть мир более рельефно и глубоко. Различие между феноменологической и естественной установками содержательно не так уж велико: то, что в естественной установке считается самим собой разумеющимся, в феноменологической становится предметом исследования, прояснения, и должно быть явно выражено.

3На это обращает внимание Л. Тенгели: Tengelyi, 2010: $15^{1 .}$ 
Известное выражение «феноменолог живет в мире смыслов», ставшее уже крылатым, является не совсем корректным и требует дальнейших разъяснений. Необходимо прояснить, прежде всего, что понимается под словом «смысл». Сложность в том, что у самого Гуссерля можно выделить как минимум два понимания этого слова: узкое и широкое. Во-первых, Гуссерль слово «смысл» часто использует чисто технически, для обозначения ядра ноэмы (узкое понимание). В этом случае утверждение, что феноменология имеет дело со смыслами, верно лишь отчасти: феноменолог также работает с ноэзисами, ассоциациями, ощущениями и т. д. Во-вторых, Гуссерль использует слово «смысл» в одном из обычных значений, какое оно имеет в выражениях «в общем смысле», «в этом смысле», «в каком смысле ты это сказал?» и т. п. Тогда верно, что феноменолог живет в мире смыслов, но, с точки зрения Гуссерля, человек в обыденной установке также живет в мире смыслов, феноменолог же делает их более выпуклыми и ясными.

\section{3. МЕТОДЫ ФЕНОМЕНОЛОГИЧЕСКОГО ИССЛЕДОВАНИЯ}

В этом разделе я не буду останавливаться на хорошо известных методах феноменологии: интенциональном анализе, дескрипции, эйдетической интуиции. Мне хотелось бы несколько подробнее остановиться на редукции и эпохе́, обратив внимание на те их функции, которые часто не замечаются, и сформулировать методологический принцип феноменологии, который Гуссерль сам не фиксирует, но постоянно использует.

Но сначала необходимо ввести представления о феноменологической установке, в которой, как принято считать, работает феноменолог. Феноменологическая установка - это особый рефлексивный способ рассмотрения опыта сознания и его предметностей, в ходе которого мы возвращаемся к уже свершившемуся опыту сознания (например, к восприятию) и заново его проживаем, попутно фиксируя новые детали данности предмета - как акта, так и его содержания, - которые при первоначальном протекании опыта не замечались.

Одна из функций эпохе́ и редукции - это переход в феноменологическую установку, который, впрочем, можно совершить и без осуществления этих процедур, путем осуществления одной только феноменологической рефлексии. Тогда все знание, все теоретические положения и утверждения автоматически останутся за рамками феноменологической установки, так как их нет в нашем конкретном опыте сознания.

Наиболее важной мне представляется другая функция эпохе́ и редукции: в ходе этих процедур выявляются и фиксируются предпосылки 
естественной установки - обыденной или научной. То, как Гуссерль поступает с ними дальше, можно разделить на три случая. Во-первых, выявленные предпосылки могут быть отброшены. Этот момент Гуссерль особо подчеркивает, например, в книге I «Идей к чистой феноменологии и феноменологической философии» (Гуссерль, Михайлов, 2002: 176-181). Действительно, некоторые из них он безоговорочно отбрасывает - например, представления современной ему психологии об обусловленности сознания материальными причинами и о принципах функционирования сознания, а также учение о существовании Бога. Но так Гуссерль поступает далеко не со всеми выявленными предпосылками. Часть из них - например, некоторые положения современного ему естествознания и логические законы, - Гуссерль проблематизирует, то есть лишает их значимости, ставит под вопрос и стремится удостовериться в них на основе обыденного опыта. Именно это Гуссерль делает в книге II «Идей к чистой феноменологии и феноменологической философии» (Husserl, 1952), в «Опыте и суждении» (Husserl, 1999) и в ряде других работ. В результате он уточняет, оправдывает или даже переформулирует некоторые положения нововременной физики, логические суждения и т. д. В раннем цикле лекций «Идея феноменологии» (Гуссерль, Артеменко, 2006) Гуссерль подвергает сомнению основную предпосылку классического познания, а именно возможность постичь трансцендентный сознанию предмет. Однако он не отбрасывает ее, а показывает, опираясь на обыденный опыт сознания, как такое постижение возможно.

Третий вариант работы с предпосылками - перенос их в само феноменологическое исследование. К сожалению, этот момент сам Гуссерль фиксирует крайне редко. Точнее говоря, Гуссерль явно определяет свою исходную позицию, не указывая при этом своих предпосылок. Например, в книге II «Идей к чистой феноменологии и феноменологической философии» он постулирует разделение действительности на три региона-материальные вещи, живые организмы и социальные личности, не называя это разделение своей предпосылкой, хотя, по моему мнению, именно таковой оно и является.

Одной из таких не фиксируемых Гуссерлем предпосылок является методологический принцип, который я формулирую следующим образом: феноменолог - это не тот, кто действует в феноменологической установке, а тот, кто постоянно удерживает различение между естественной и феноменологической установками. Обоснование этому тезису можно дать следующее. 
Прежде всего, сам предмет исследования берется из естественной установки - обыденной или научной. Для того, чтобы исследовать предмет, нужно не только начинать с его данности в нашем опыте сознания в естественной установке, но и всегда «иметь его перед собой», чтобы соотносить результаты исследования с тем, что исследуется. Именно поэтому Гуссерль постоянно повторяет, что редукция - это не мгновенный процесс, а процедура, которая должна осуществляться постоянно. Исходя из этого, сам процесс редукции можно обозначить как теоретическую рефлексию, направленную на естественную установку и выявляющую ее предпосылки.

Кроме того, важно отметить, что цели и задачи своих исследований, определение предмета исследований, методы своей работы Гуссерль формулирует в естественной теоретической установке. И то, что в феноменологической установке он продолжает придерживаться этих целей, задач, методов и предмета, является показателем совмещения Гуссерлем феноменологической и естественной установок в своей работе. $\mathrm{K}$ конкретным примерам я обращусь чуть ниже при рассмотрении основных областей интересов Гуссерля.

Здесь хотелось бы указать на один из возможных истоков принципа работы в двух установках, который можно найти в определении интенциональности Брентано:

Всякий психический феномен характеризуется посредством того, что средневековые схоласты называли интенциональным (или же ментальным) внутренним существованием предмета, и что мы, хотя и в несколько двусмысленных выражениях, назвали бы отношением к содержанию, направленностью на объект (под которым здесь не должна пониматься реальность), или имманентной предметностью. Любой психический феномен содержит в себе нечто в качестве объекта, хотя и не одинаковым образом. В представлении нечто представляется, в суждении нечто признается или отвергается, в любвилюбится, в ненависти-ненавидится и т. д. (Брентано, Анашвили, 1996: 33).

Это определение вызвало много споров среди исследователей творчества Брентано именно потому, что оно дается одновременно из двух установок. Определение интенциональности как направленности на объект дается в естественной установке, а как психического феномена, содержащего в себе сам объект,- в феноменологической, то есть с точки зрения сознания. Эта двойственность остается и у Гуссерля. Иногда он говорит об интенциональности как о свойстве сознания быть сознанием, направленным на предмет, а иногда - как о свойстве сознания быть 
сознанием о чем-то. Это второе определение допускает интерпретацию, согласно которой предмет содержится в самом сознании.

Другой пример смешения установок можно наблюдать в аналитических толкованиях феноменологии Гуссерля, например, в их интерпретациях ноэмы и смысла. Я имею в виду работы Д. Фёллесдаля (Føllesdal, 1969: 680-687), И. Моханти (Mohanty, 1964) и других исследователей (в российской традиции-Е. В. Борисова 4$)$. Главная их ошибка, на мой взгляд, состоит в том, что аналитические интерпретаторы в состав ноэмы включили реальный предмет. Но исходя из того, что ноэма может быть выделена только в феноменологической установке, то есть в рефлексивной позиции, вести речь о реальном предмете в ее составе невозможно. Когда Гуссерль говорит о предмете как некотором $X$, имеется в виду не реальный предмет, а виртуальная точка сосредоточения ноэматических смыслов. Это является предпосылкой Гуссерля, которую он перенес как предпосылку тождественности предмета из естественной установки.

\section{4. СФЕРЫ ПРЕДМЕТНЫХ ИНТЕРЕСОВ ГУССЕРЛЯ}

Русский философ Г. Г. Шпет считал, что «все может быть объектом феноменологии, начиная вот с этой сожженной спички и пепла, и вплоть до мирового и надмирового целого» (Шпет, 1996: 52). Это высказывание с полным правом можно отнести к философии Гуссерля. Тем не менее, охватывая взглядом опубликованные тома Гуссерлианы, можно, с определенными оговорками, выделить три сферы интересов Гуссерля, чаще всего приковывавших его внимание: изучение сознания, разрешение проблем теории познания и исследование окружающего мира. Коротко обратимся к каждой из этих сфер с точки зрения заявленных принципов феноменологии.

Исследованию сознания посвящено, наверное, большинство трудов Гуссерля, в силу чего феноменологию часто называют философией сознания. Гуссерль отбрасывает все современные ему подходы к сознанию с их предпосылками и результатами и разрабатывает свое собственное, основанное отчасти на идеях Брентано, понимание сознания. При этом тот факт, что основным свойством сознания Гуссерль называет интенциональность, можно считать его предпосылкой (несмотря на то, что интенциональность обнаруживается в реальном опыте сознания), хотя он не маркирует ее как таковую. В гуссерлевских штудиях сознания

${ }^{4}$ См. например: Борисов, 1996. 
можно выделить две линии: анализ сознания на основе опыта и построение модели сознания. Нередко эти линии присутствуют в одних и тех же работах (Шиян, 2012: 38-47).

Анализ сознания на основе опыта сознания Гуссерль осуществляет как с теоретической рефлексивной позиции, так и в рамках феноменологической установки. В теоретической рефлексивной установке наше внимание направляется на то, как «в общем» протекает тот или иной опыт сознания. Таковы описание основных структур сознания - ноэмы и ноэзиса - в книге I «Идей к чистой феноменологии и феноменологической философии», классификация модусов сознания во втором томе «Логических исследований» (Гуссерль, Молчанов, 2011) и выявление отношений между ними, выделение основных признаков различных модусов сознания - восприятия и фантазии - в «Пыте и суждении» и в курсе лекций «Вещи и пространство» (Husserl, 1973) и т. д. При этом Гуссерль пользуется эйдетической интуицией (хотя и не всегда обращает на это внимание), так как речь идет об общих признаках и свойствах сознания, которые присущи любому индивидуальному опыту сознания. Также Гуссерль при исследовании сознания работает и в рамках феноменологической установки, то есть описывает поэтапно, «изнутри», как протекают сами процессы восприятия, фантазии и других способов данности определенного предмета.

Однако рядом с описанием опыта сознания у Гуссерля нередко соседствует моделирование этого опыта. Речь идет, прежде всего, о схеме «хюле (ощущения) - чувственный акт». То есть Гуссерль пытается сконструировать, что было до того, как мы увидели конкретный предмет: изначально нам даны бесформенные ощущения, которые оживляются актом сознания, в результате чего формируется предмет, который мы видим. Поскольку в реальном опыте очень сложно представить изначальные, то есть допредметные, ощущения и практически невозможно обнаружить оживляющий их акт, то можно констатировать, что здесь Гуссерль отходит от основного принципа феноменологии удостоверять все свои результаты на опыте. К работам, связанным с конструированием сознания, можно отнести и поздние манускрипты Гуссерля по внутреннему сознанию-времени, где он пытается, обращаясь к глубинным слоям сознания, воспроизвести процесс формирования потока сознания из первичной импрессии.

Хотелось бы обратить внимание на еще один факт отклонения от принципа «обоснованности опытом» в гуссерлевских исследованиях сознания. Дело в том, что Гуссерль проводит свое исследование сознания так, как 
будто оно абсолютно и единственно верно. То есть он как бы забывает, что сознание обусловлено определенными предпосылками и поэтому не может предоставить единственно верного на все времена результата. Гуссерль как раз убежден, что такой результат достижим. Во всех исследованиях сознания он как бы реализует идею, высказанную еще в 6-м «Логическом исследовании», что в рефлексии, то есть при анализе самого сознания, можно достичь аподиктической очевидности (Husserl, 1984: 645-651), то есть истины. Кроме того, хотелось бы подчеркнуть, что Гуссерль, даже исследуя реальный опыт сознания, не описывает сам тот опыт, в котором ему даны переживания сознания. То есть он описывает результат рефлексии, но не то, как она протекает. Возможно ли вообще совершить это описание, для меня открытый вопрос.

Вторая важная сфера интересов Гуссерля-это сфера познания. Гуссерль здесь рассматривает следующие проблемы: достижение трансцендентного, образование общих понятий, статус общих сущностей, природа логических суждений, достижение истины, ее критерий и другие. Для решения этих проблем Гуссерль обращается к нашему обыденному опыту сознания и использует уже полученные им результаты исследования сознания. Но можно сказать и наоборот: в ходе решения проблем познания оттачиваются гуссерлевские дескрипции обыденного опыта сознания. Проблематика теории познания представлена по большей части в так называемом логическом цикле Гуссерля, к которому относятся «Логические исследования», «Опыт и суждение», «Формальная и трансцендентальная логика» (Husserl, 1974), «Лекции по логике и теории познания» (Husserl, 1985) и другие работы.

В сфере исследования проблем познания ярко проявляется принцип работы в двух установках. Так, первоначально колеблясь в вопросе о том, как протекает эйдетическая (интеллектуальная) интуиция, Гуссерль все же склоняется к тому, что она осуществляется не в рефлексивной позиции, то есть требует выхода за пределы феноменологической установки. Это подтверждается и его описанием метода вариации для определения сущности предмета. Для этого необходимо осуществить возможные опыты с данным предметом - в фантазии, а не в рефлексии, - чтобы после в феноменологической установке определить, какой признак для предмета является сущностным. Другой пример работы Гуссерля в двух установках - это приведение данности предмета к очевидности. Оно осуществляется сначала в естественной установке (у Гуссерля в опыте восприятия), а его результаты анализируются и проверяются на очевидность/истинность уже в феноменологической установке. 
Третья сфера интересов Гуссерля - исследование окружающего мира. Предпосылкой Гуссерля в этой области (не маркируемой им в качестве предпосылки) является, как я уже отмечала выше, понимание мира как совокупности вещей из свойств и отношений между ними. Для него исследовать вещи значит исследовать тот реальный опыт, в котором они даны. Именно поэтому исследование вещей у Гуссерля неотделимо от исследования опыта сознания и нередко осуществляется в одних и тех же работах. Хотя и можно выделить, с одной стороны, такие работы, как «Кризис европейских наук и трансцендентальную феноменологию» (Гуссерль, Скляднев, 2004), а также XXIII и XXXIX тома Гуссерлианы (Husserl, 1992; 2008), которые специально посвящены тематике жизненного мира, а с другой - книги II и III «Идей к чистой феноменологии и феноменологической философии» (Husserl, 1952; 1971) и другие работы, в которых не вводится понятие жизненного мира, но также исследуется окружающий мир и науки о нем. Научные результаты, как считает Гуссерль, тоже могут относиться к вещам реального мира, но только в том случае, если они могут быть удостоверены нашим обыденным опытом и будет показано происхождение научных абстракций из опыта жизненного мира.

Как же понимал Гуссерль мир и может ли в нашем опыте «сама вещь» быть дана целиком и полностью? Наш опыт вещи бесконечен, и в ходе него мы можем открывать все новые и новые стороны исследуемой вещи. Полностью вещь может быть схвачена в виде идеи, которая и направляет все дальнейшее протекание опыта. Для меня все еще открыт вопрос, остается ли возможность бесконечного познания вещи в свете этой идеи предпосылкой нашего обыденного опыта, которую Гуссерль перенес в свои исследования, или это его собственная предпосылка, которая является требованием для всякого, идущего его путем.

Здесь хотелось бы уточнить ранее сказанное. Дело не только в том, что определить, что именно существует, мы можем только на основе собственного опыта, но и в том, что сам наш опыт уже помещен в контекст определенной установки, направленной на исследование материальных вещей, живых существ или социальных личностей. То есть наше знание всегда обусловлено некоторыми предпосылками и некоторой установкой, и утверждать что-то «абсолютно», без учета этого контекста, мы не можем.

Вопрос об окружающем мире на языке Гуссерля звучит как вопрос о конституировании смысла мира, смысла вещей, положений дел и отношений. Однако понятие конституирования имеет в исследованиях 
Гуссерля как минимум два противоположных значения. Не случайно Финк (Финк, Шиян, 2008: 361-381) отнес его к «оперативным понятиям» Гуссерля, то есть к таким, смысл которых тот сам однозначно не определяет, хотя и часто их использует. Конституирование в первом значении можно понимать как описание того обыденного опыта, в котором нам даны конкретные предметы и положения дел,- в ходе такого описания мы более глубоко и рельефно понимаем их.

В этом случае феноменологическое исследование руководствуется вопросом: «Каков мир, который нас окружает?» Ответы подразумевают выявление основных различий, структур окружающего мира, которые имеют свое оправдание в обыденном опыте. Безусловно, особо нужно отметить исследования самого обыденного опыта, благодаря которому нам дан окружающий мир. Эту задачу продолжили последователи Гуссерля, к которым можно отнести, прежде всего, Щюца и Хельда.

Конституирование во втором значении-это синоним конструирования или производства. В этом случае мы попадаем в другое понимание феноменологии, которое руководствуется вопросом: «Почему окружающий нас мир именно таков, каков он есть?» Этот вопрос отсылает к исследованию того, как сформировался (образовался) тот мир, который нас окружает. Такие исследования нельзя провести на основе нашего личного опыта. Мы либо погружаемся в теоретическое конструирование того, как из хаоса ощущений (хюле) возникает целостная вещь, либо рассматриваем «внешние причины»-культурные, экономические, социальные и прочие, - благодаря которым сформировался тот мир, в котором мы живем. Неслучайно, что подобными исследованиями занимаются и другие философские подходы,- например, философия Гегеля или Маркса. Однако они не обязательно противоречат феноменологическому подходу. Если теоретические конструкты могут быть сведены к нашему опыту и разъяснены исходя из него, то они соответствуют действительности. Но здесь возникают сложности с гегелевской философией, поскольку в ней отсутствует одна из важнейших предпосылок феноменологии - предпосылка существования материального мира, который у Гегеля появляется лишь на определенном этапе развития мирового духа. По-другому это можно выразить так: у Гуссерля принципиально невозможен переход смысла в предмет, идеального в материальное и наоборот. Для того, чтобы обнаружить «идеальный мир»который, кстати, не имеет реального статуса существования,- -необходима смена установок скачками; о плавном переходе не может идти речи. 


\section{5. ЗАКЛЮЧЕНИЕ}

В заключение мне хотелось бы оценить свой подход к пониманию феноменологии с точки зрения оппозиции «презентизм-антикваризм», используемой в отечественной истории науки (Кузнецова, 2009: 164-196). Сторонники антикваризма ставят целью восстановить событие, в нашем случае - феноменологию Гуссерля, в его исторической подлинности и уникальности; сторонники презентизма оценивают историческое событие, исходя из современного им уровня научного знания, терминологического аппарата, интересов и т. п. Представленная мною позиция является презентистской в том смысле, что смотрит на феноменологию с точки зрения, которая кажется наиболее перспективной именно сегодня.

$\mathrm{C}$ точки зрения представленного мной подхода, нет нужды обращаться к таким разделам философии Гуссерля, как конструкция чистого Я, теория интерсубъективности, развиваемая в «Картезианских медитациях» или анализ конституирования глубинных слоев сознания-времени. $\mathrm{C}$ точки зрения современных перспектив феноменологии, эти моменты кажутся несущественными. Однако позиция тех, кто понимает феноменологию только как науку о «чистом Я», тоже является презентистской, поскольку они также не рассматривают позицию Гуссерля во всей его исторической сложности, а закрывают глаза на некоторые другие аспекты-например, на понятие «опыта» и роль рефлексии у Гуссерля. В защиту презентизма, который в отечественной истории науки играет скорее негативную роль, можно сказать, что в изучении истории философии он дает ей шанс стать философией. И этим шансом воспользовался Гуссерль, заново переосмыслив используемые до него понятия и методы.

\section{Источники}

Брентано $Ф$. Психология с эмпирической точки зрения // Избранные работы / пер. с нем. В. В. Анашвили. - М. : Дом интеллектуальной книги, 1996. C. $11^{-91}$.

Гуссерль Э. Начало геометрии / введ. Ж. Деррида ; пер. с нем. М. А. Маяцкого. M. : Ad Marginem, 1996.

Гуссерль Э. Идеи к чистой феноменологии и феноменологической философии / пер. с нем. А. В. Михайлова. - М. : Академический проект, 2002.

Гуссерль Э. Кризис европейских наук и трансцендентальная феноменология / пер. с нем. Д. В. Скляднева. - СПб. : Фонд «Университет», Владимир Даль, 2004 .

Гуссерль Э. Идея феноменологии / пер. с нем. А. А. Артеменко. - СПб. : Гуманитарная Академия, 2006. 
Гуссерль Э. Картезианские медитации / пер. с нем. В. И. Молчанова. - М. : Академический проект, 2010.

Гуссерль Э. Логические исследования. Том II / пер. с нем. В. И. Молчанова. M. : Академический проект, 2011.

Husserl E. Ideen zu einer reinen Phänomenologie und phänomenologischen Philosophie. Zweites Buch: Phänomenologische Untersuchungen zur Konstitution / hrsg. von M. Biemel. - Den Haag : Martinus Nijhoff, 1952. - (Husserliana ; 4). Husserl E. Erste Philosophie (1923/4). Zweiter Teil: Theorie der phänomenologischen Reduktion / hrsg. von R. Boehm. - Den Haag : Martinus Nijhoff, 1959. (Husserliana ; 8).

Husserl E. Ideen zur einer reinen Phänomenologie und phänomenologischen Philosophie. Drittes Buch: Die Phänomenologie und die Fundamente der Wissenschaften / hrsg. von M. Biemel. - Den Haag : Martinus Nijhoff, 1971. - (Husserliana ; 5).

Husserl E. Ding und Raum. Vorlesungen 1907 / hrsg. von U. Claesges. - Den Haag : Martinus Nijhoff, 1973. - (Husserliana ; 16).

Husserl E. Formale and transzendentale Logik. Versuch einer Kritik der logischen Vernunft / hrsg. von P. Janssen. - Den Haag : Martinus Nijhoff, 1974. - (Husserliana ; 17).

Husserl E. Logische Untersuchungen. Zweiter Teil. Untersuchungen zur Phänomenologie und Theorie der Erkenntnis. In zwei Bänden / hrsg. von U. Panzer. Den Haag : Martinus Nijhoff, 1984. - (Husserliana ; 19).

Husserl E. Einleitung in die Logik und Erkenntnistheorie. Vorlesungen 1906/o7 / hrsg. von U. Melle. - Den Haag : Martinus Nijhoff, 1985. - (Husserliana ; 24). Husserl E. Die Krisis der europaischen Wissenschaften und die transzendentale Phänomenologie. Ergänzungsband. Texte aus dem Nachlass 1934-1937 / hrsg. von R. N. Smid. - Den Haag : Kluwer Academic Publishers, 1992. - (Husserliana ; 29).

Husserl E. Erfahrung und Urteil. - Hamburg : Meiner, 1999.

Husserl E. Die Lebenswelt. Auslegungen der vorgegebenen Welt und ihrer Konstitution. Texte aus dem Nachlass (1916-1939) / hrsg. von R. Sawa. - Dordrecht : Springer, 2008. - (Husserliana ; 39).

\section{ЛИтеРАTУРA}

Борисов E. B. «Явление и смысл» Г. Шпета в контексте развития феноменогии Э. Гуссерля // Явление и смысл / Г. Г. Шпет. - Томск : Водолей, 1996. C. $183^{-191 .}$

Кузнецова Н. И. Презентизм и антикваризм - две картины прошлого // Arbor Mundi. - 2009. - № 15 .

Молчанов В. И. Исследования по феноменологии сознания. - М. : Территория будущего, 2007.

Финк О. Оперативные понятия феноменологии Гуссерля / пер. с нем. А.А. Шиян // Ежегодник по феноменологической философии. Т. І. - М. : Издательство РГГУ, 2008. - С. 361-381. 
Шиян А. А. Проблема восприятия у раннего Гуссерля // Философия. Язык. Культура. - СПб. : Алетейя, 2012. - С. 38-47.

Шиян A. А. Трансцендентность мира и трансцендентность предмета в феноменологии Гуссерля // Ежегодник по феноменологической философии. T. IV. М. : Издательство РГГУ, 2015. - С. 213-233.

Шnem Г. Г. Явление и смысл. - Томск : Водолей, 1996.

Føllesdal D. Husserl's Notion of Noema // Journal of Philosophy. - 1969. - Vol. 66. P. $680-687$.

Gallagher S., Zahavi D. The Phenomenological Mind. - London, New York : Routledge, 2012.

Held K. Die Endlichkeit der Welt. Phänomenologie im Übergang von Husserl zu Heidegger // Philosophie der Endlichkeit. Festschrift für Erich Christian Schroder zum 65 / hrsg. von B. Niemeyer, D. Schutze. - Wurzburg : Geburtstag, 1992. S. $130^{-145}$.

Mohanty J. Edmund Husserl's Theory of Meaning. - The Hague : Martinus Nijhoff, 1964 .

Tengelyi L. Husserls methodologischer Transzendentalismus // Philosophy, Phenomenology, Sciences. Essays in Commemoration of Edmund Husserl / hrsg. von C. Ierna, H. Jacobs, F. Mattens. - Dordrecht : Springer, 2010. - S. 135-153.

Tengelyi L. Welt und Unendlichkeit. Zum Problem phänomenologischer Metaphysik. - Freiburg, München : Alber, 2014.

Shiyan, A. A. 2017. "Ontologicheskiye i metodologicheskiye printsipy fenomenologicheskogo podkhoda Edmunda Gusserlya [Ontological and Methodological Principles of the Phenomenological Approach of Edmund Husserl]" [in Russian]. Filosofiya. Zhurnal Vysshey shkoly ekonomiki [Philosophy. Journal of the Higher School of Economics] I (3), 63-79.

\section{ANNA SHIYAN}

PhD in Philosophy; Associate Professor of the Chair of Social Philosophy, Department of Philosophy, Russian State Univerisity for the Humanities (Moscow)

\section{Ontological and Methodological Principles of the Phenomenological Approach of Edmund Husserl}

Abstract: Recognizing the validity of the many interpretations of Husserl's phenomenology, author proposes and substantiates her own approach to Husserl's philosophy, based on the works of K. Held, V. I. Molchanov, and L. Tengely. For this purpose, she formulates the ontological premises of Husserl's philosophy, which determined his research, although they were not always clearly expressed by him. These premises include the recognition of the existence of the world as a collection of objects, their properties, and relationships. Furthermore, the author dwells on the principles and methods of phenomenological research. She takes into account not only and not so much Husserl's own declaration of his principles, but also their specific application and implementation in the real phenomenological work. As a result, the "new" (not designated as such by Husserl himself) principles of the phenomenological approach 
are formulated and the "old" and well-known ones are rethought. The article focuses on the method of the epoché and the principle of operation in natural and phenomenological attitudes. The author considers identification of the premises of a natural attitude, some of which are transferred to a phenomenological one, to be one of the most important functions of epoché. In the article it is also demonstrated how Husserl's ontological and methodological premises are applied in his works, devoted to study of consciousness, resolution of problems of the theory of knowledge and exploring the world around. In the course of these considerations, the author refers to the point in which Husserl departs from his principles and starts to follow another strategy, a constructivist one. This refers first of all to an understanding of intentionality, concepts of meaning and noema, and application of the method of the reduction. Finally, while evaluating her own strategy for studying Husserl's philosophy, the author denotes her historical-philosophical approach as a presentist one.

Keywords: Phenomenology, Husserl, Experience of Consciousness, Reduction, Phenomenological Attitude.

\section{REFERENCES}

Borisov, Ye.V. 1996. "'Yavleniye i smysl' G. Shpeta v kontekste razvitiya fenomenogii E. Gusserlya ['Appearance and Sense' of G. Shpet in the Context of the Development of E. Husserl's Phenomenology]" [in Russian]. In Shpet 1996, 183-191.

Brentano, F. 1996. Psikhologiya s empiricheskoy tochki zreniya [Psychologie vom empirischen Standpunkt] [in Russian]. In Izbrannyye raboty [Selected works], trans. from the German by V. V. Anashvili, 11-91. Moskva [Moscow]: Dom intellektual'noy knigi.

Fink, O. [Fink, E.] 2008. "Operativnyye ponyatiya fenomenologii Gusserlya [Operative Begriffe in Husserls Phänomenologie]" [in Russian]. In vol. I of Yezhegodnik po fenomenologicheskoy filosofii [Annual for Phenomenological Philosophy], trans. from the German by A. A. Shiyan, 361-381. Moskva [Moscow]: Izdatel'stvo RGGU.

Føllesdal, D. 1969. "Husserl's Notion of Noema." Journal of Philosophy 66:680-687.

Gallagher, Sh., and D. Zahavi. 2012. The Phenomenological Mind. London and New York: Routledge.

Gusserl', E. [Husserl, E.] 1996. Nachalo geometrii [Ursprung der Geometrie] [in Russian]. Trans. from the German by M. A. Mayatskiy. Moskva [Moscow]: Ad Marginem.

- . 2002. Idei $k$ chistoy fenomenologii $i$ fenomenologicheskoy filosofii [Ideen zu einer reinen Phänomenologie und phänomenologischen Philosophie. Erstes Buch: Allgemeine Einführung in die reine Phänomenologie] [in Russian]. Trans. from the German by A. V. Mikhaylov. Moskva [Moscow]: Akademicheskiy proyekt.

- . 2004. Krizis yeuropeyskikh nauk i transtsendental'naya fenomenologiya [Die Krisis der europäischen Wissenschaften und die transzendentale Phänomenologie] [in Russian]. Trans. from the German by D. V. Sklyadnev. Sankt-Peterburg [Saint Petersburg]: Fond "Universitet" / Vladimir Dal'.

- . 2006. Ideya fenomenologii [Die Idee der Phänomenologie] [in Russian]. Trans. from the German by A. A. Artemenko. Sankt-Peterburg [Saint Petersburg]: Gumanitarnaya Akademiya.

- . 2010. Kartezianskiye meditatsii [Cartesianische Meditationen] [in Russian]. Trans. from the German by V. I. Molchanov. Moskva [Moscow]: Akademicheskiy proyekt.

- . 2011. Logicheskiye issledovaniya. Tom II [Logische Untersuchungen. Zweiter Teil. Untersuchungen zur Phänomenologie und Theorie der Erkenntnis] [in Russian]. Trans. from the German by V.I. Molchanov. Moskva [Moscow]: Akademicheskiy proyekt. 
Held, K. 1992. "Die Endlichkeit der Welt. Phänomenologie im Übergang von Husserl zu Heidegger" [in German]. In Philosophie der Endlichkeit. Festschrift für Erich Christian Schroder zum 65, ed. by B. Niemeyer and D. Schutze, 130-145. Wurzburg: Geburtstag.

Husserl, E. 1952. Ideen zu einer reinen Phänomenologie und phänomenologischen Philosophie. Zweites Buch: Phänomenologische Untersuchungen zur Konstitution [in German]. Ed. by M. Biemel. Husserliana 4. Den Haag: Martinus Nijhoff.

- . 1959. Erste Philosophie (1923/4). Zweiter Teil: Theorie der phänomenologischen Reduktion [in German]. Ed. by R. Boehm. Husserliana 8. Den Haag: Martinus Nijhoff.

- . 1971. Ideen zur einer reinen Phänomenologie und phänomenologischen Philosophie. Drittes Buch: Die Phänomenologie und die Fundamente der Wissenschaften [in German]. Ed. by M. Biemel. Husserliana 5. Den Haag: Martinus Nijhoff.

- . 1973. Ding und Raum. Vorlesungen 1907 [in German]. Ed. by U. Claesges. Husserliana 16. Den Haag: Martinus Nijhoff.

- . 1974. Formale and transzendentale Logik. Versuch einer Kritik der logischen Vernunft [in German]. Ed. by P. Janssen. Husserliana 17. Den Haag: Martinus Nijhoff.

- . 1984. Logische Untersuchungen. Zweiter Teil. Untersuchungen zur Phänomenologie und Theorie der Erkenntnis. In zwei Bänden [in German]. Ed. by U. Panzer. Husserliana 19. Den Haag: Martinus Nijhoff.

- . 1985. Einleitung in die Logik und Erkenntnistheorie. Vorlesungen 1906/or [in German]. Ed. by U. Melle. Husserliana 24. Den Haag: Martinus Nijhoff.

- 1992. Die Krisis der europaischen Wissenschaften und die transzendentale Phänomenologie. Ergänzungsband. Texte aus dem Nachlass 1934-1937 [in German]. Ed. by R. N. Smid. Husserliana 29. Den Haag: Kluwer Academic Publishers.

- . 1999. Erfahrung und Urteil [in German]. Hamburg: Meiner.

- . 2008. Die Lebenswelt. Auslegungen der vorgegebenen Welt und ihrer Konstitution. Texte aus dem Nachlass (1916-1939) [in German]. Ed. by R. Sawa. Husserliana 39. Dordrecht: Springer.

Kuznetsova, N. I. 2009. "Prezentizm i antikvarizm - dve kartiny proshlogo [Presentism and Antiquarism as Two Pictures of the Past]" [in Russian]. Arbor Mundi, no. 15.

Mohanty, J. 1964. Edmund Husserl's Theory of Meaning. The Hague: Martinus Nijhoff.

Molchanov, V. I. 2007. Issledovaniya po fenomenologii soznaniya [Studies on the Phenomenology of Consciousness] [in Russian]. Moskva [Moscow]: Territoriya budushchego.

Shiyan, A. A. 2012. "Problema vospriyatiya u rannego Gusserlya [The Problem of Perception in the Early Husserl]" [in Russian]. In Filosofiya. Yazyk. Kul'tura [Philosophy. Language. Culture], 38-47. Sankt-Peterburg [Saint Petersburg]: Aleteyya.

- . 2015. "Transtsendentnost' mira i transtsendentnost' predmeta v fenomenologii Gusserlya [The Transcendence of the World and the Transcendence of the Object in Husserl's Phenomenology]" [in Russian]. In vol. IV of Yezhegodnik po fenomenologicheskoy filosofii [Annual for Phenomenological Philosophy], 213-233. Moskva [Moscow]: Izdatel'stvo RGGU.

Shpet, G. G. 1996. Yavleniye i smysl [Appearance and Sense] [in Russian]. Tomsk: Vodoley.

Tengelyi, L. 2010. "Husserls methodologischer Transzendentalismus" [in German]. In Philosophy, Phenomenology, Sciences. Essays in Commemoration of Edmund Husserl, ed. by C. Ierna, H. Jacobs, and F. Mattens, 135-153. Dordrecht: Springer.

- . 2014. Welt und Unendlichkeit. Zum Problem phänomenologischer Metaphysik [in German]. Freiburg and München: Alber. 